Technological University Dublin ARROW@TU Dublin

2020

\title{
Association between eccentric knee flexor strength and hamstring injury risk in 185 elite Gaelic football players
}

\author{
Mark Roe \\ University College Dublin \\ Eamonn Delahunt \\ University College Dublin \\ Malachy McHugh \\ New York University
}

See next page for additional authors

Follow this and additional works at: https://arrow.tudublin.ie/ittsciart

Part of the Sports Medicine Commons

\section{Recommended Citation}

Roe M, Delahunt E, McHugh M, et al. Association between eccentric knee flexor strength and hamstring injury risk in 185 elite Gaelic football players. Scand J Med Sci Sports. 2020;00:1-8. DOI: 10.1111/ sms.13588

This Article is brought to you for free and open access by the School of Science and Computing at ARROW@TU Dublin. It has been accepted for inclusion in Articles by an authorized administrator of ARROW@TU Dublin. For more information, please contact arrow.admin@tudublin.ie, aisling.coyne@tudublin.ie, gerard.connolly@tudublin.ie.

Funder: Gaelic Athletic Association

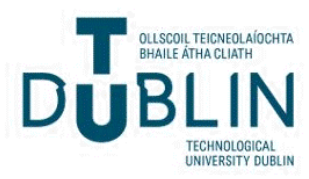




\section{Authors}

Mark Roe, Eamonn Delahunt, Malachy McHugh, Conor Gissane, Shane Malone, Kieran Collins, and Catherine Blake 


\title{
Association between eccentric knee flexor strength and hamstring injury risk in 185 elite Gaelic football players
}

\author{
Mark Roe $^{1}$ (D) | Eamonn Delahunt ${ }^{1,2}$ | Malachy McHugh ${ }^{3,4}$ | Conor Gissane ${ }^{5}$ | \\ Shane Malone $^{6,7}$ (i) | Kieran Collins $^{6}$ | Catherine Blake ${ }^{1}$
}

\author{
${ }^{1}$ School of Public Health, Physiotherapy \\ and Sports Science, University College \\ Dublin, Dublin, Ireland \\ ${ }^{2}$ Institute for Sport and Health, University \\ College Dublin, Dublin, Ireland \\ ${ }^{3}$ Department of Physical Therapy, New \\ York University, New York, NY, USA \\ ${ }^{4}$ Nicholas Institute of Sports Medicine and \\ Athletic Trauma, Lenox Hill Hospital, New \\ York, NY, USA \\ ${ }^{5}$ School of Sport, Health and Applied \\ Science, St Mary's University, Twickenham, \\ UK \\ ${ }^{6}$ Department of Science, Gaelic Sports \\ Research Centre, Institute of Technology \\ Tallaght, Dublin, Ireland \\ ${ }^{7}$ Research Institute for Sport and Exercise \\ Sciences, Liverpool John Moores \\ University, Liverpool, UK

\section{Correspondence} \\ Mark Roe, School of Public Health, \\ Physiotherapy and Sports Science, \\ University College Dublin, Dublin, Ireland. \\ Email: mark.roe@ucd.ie \\ Funding information \\ Gaelic Athletic Association
}

Hamstring strains are the most common time-loss injury in elite Gaelic football affecting over $20 \%$ of players per season. Thus, there is a need to identify factors contributing to the onset of hamstring injuries in order to inform injury risk management strategies. The current study investigated whether eccentric knee flexor strength and between-limb imbalances were associated with increased risk of sustaining a timeloss hamstring injury in elite Gaelic football players. A total of 185 elite male players $(26.9 \pm 2.7$ years, $86.4 \pm 6.2 \mathrm{~kg}, 183.4 \pm 5.6)$ were prospectively followed for 12 weeks from the day of testing. Injury data were provided by the team medical staff. Twenty-eight players (16\%) sustained a time-loss hamstring injury following testing. Players that did not sustain a hamstring injury had greater average betweenlimb asymmetries (uninjured $=9.1 \%, 95 \%$ CI 7.8-10.1; injured $=5.1 \%, 95 \% \mathrm{CI}$ 3.7-6.7; $P=.001)$. Eccentric knee flexor strength profiles were not associated with increased or decreased risk of sustaining a hamstring injury and did not alter the post-test probability of sustaining a hamstring injury across the investigation period. These findings do not support the use of eccentric knee flexor strength metrics in managing hamstring injury risk in elite male Gaelic football players.

\section{K E Y W OR D S}

Gaelic football, hamstring, injury, risk factor

\section{1 | INTRODUCTION}

Hamstring injuries are the most common time-loss injury in elite Gaelic football. ${ }^{1}$ The median rate of hamstring injuries is nine per team-season, affecting $21 \%$ of players and accounting for $33 \%$ of player unavailability. ${ }^{1}$ Despite interventions showing efficacy in reducing risk of hamstring injuries, rates appear to be increasing in elite Gaelic football and elite soccer. $^{1-3}$

Modifiable risk factors for hamstring injuries have been identified in elite field sports using metrics derived from an eccentric knee flexor strength assessment. For example, in elite rugby union, eccentric strength imbalances of $\geq 10 \%$ and $\geq 15 \%$ were associated with a relative risk (RR) of 1.4 and 2.4 for future injury, respectively. ${ }^{4}$ Similarly, preseason eccentric hamstring strength levels of $<256 \mathrm{~N}$ were associated with increased injury risk in elite Australian football players $(\mathrm{RR}=2.7) .^{5}$ Elite soccer players with eccentric hamstring strength levels of $<337 \mathrm{~N}$ have also been identified as being more susceptible to injury $(\mathrm{RR}=4.4)$ than their stronger peers. ${ }^{6}$ Conversely, risk of sustaining a hamstring injury did not differ between professional soccer players with low 
$(<1 \mathrm{SD}$ below the mean) or high ( $>1 \mathrm{SD}$ above the mean) preseason eccentric hamstring strength levels. ${ }^{7}$

To date, only one risk factor for sustaining a hamstring injury has been identified in elite Gaelic football. ${ }^{1}$ Specifically, players with a previous hamstring injury were 3.3 times more likely to sustain a hamstring injury within the subsequent season compared to their uninjured counterparts. However, 64\% of hamstring injuries are not recurrent. ${ }^{1}$ Thus, there is a need to identify high risk players using factors other than injury history. Therefore, the aim of the current study was to evaluate whether eccentric knee flexor strength and between-limb imbalances increased risk of sustaining a hamstring injury in elite Gaelic football.

\section{2 | MATERIALS AND METHODS}

A total of 185 elite Gaelic football players $(26.9 \pm 2.7$ years, $86.4 \pm 6.2 \mathrm{~kg}, 183.4 \pm 5.6$ ) from five separate adult teams participated in the study. Three teams played senior level $(\mathrm{n}=118)$, while two teams played under-20 level (ie, the next most senior grade) $(n=68)$. This represents $17 \%$ of elite senior division one and two players and $8 \%$ of elite U20 players.

All players previously participated in a separate investigation aiming to report eccentric knee flexor strength values of elite Gaelic football players from underage to adult level while also examining the influence of body mass and previous hamstring injury. ${ }^{8}$

\section{1 $\quad$ Assessment}

Testing was completed in preseason (November 20 to January $5 ; \mathrm{n}=161 ; 87 \%$ ) or National League (March 20; $\mathrm{n}=24 ; 13 \%$ ) cycles at dates convenient to team schedules. The main competitive cycle began on May 6 .

Players were required to complete a questionnaire prior to strength testing to establish their dominant leg and previous injury history. The Oslo Sports Trauma Research Center questionnaire on health problems was completed as described by the London 2012 Injury and Illness Surveillance Project. ${ }^{9}$ Questions focused on four domains: participation in normal training and competition during the past week, training volume during the past week, performance during the past week, and symptoms/health complaints during the past week. Substantial health problems were classified as any injury or illness "leading to moderate or severe reductions in training volume, or moderate or severe reductions in sports performance, or complete inability to participate in sport." 9

A prototype of the portable strength testing device (Nordbord, Vald Performance) has previously shown to display high-to-moderate reliability (intraclass correlation coefficient $=.83-.90$; typical error, 21.7-27.5 N; typical error as a coefficient of variation, $5.8 \%-8.5 \%) .{ }^{10} \mathrm{~A}$ prior investigation involving the current participants also found that body mass accounted for only $3 \%$ of the variance in maximum eccentric knee flexor force among elite Gaelic football players aged $>21$ years. $^{8}$

A previously described protocol was utilized for the current study. ${ }^{8}$ That is, following a warm-up set, participants performed one set of three maximal repetitions of the Nordic hamstring exercise on the device. Beyond this, we were unable to account for familiarity with the exercise. Raw data were exported into a customized spreadsheet (Microsoft). All testing was conducted by MR on a single device transported to multiple locations. Data relating to maximum force and average force for each leg, as well as between-limb imbalances, were derived from the excel sheet.

\subsection{Injury reporting}

Injury data were provided by the team medical staff. Injury diagnosis was made by the team chartered physiotherapist or medical doctor. Hamstring injuries were recorded using time-loss definition, that is, as preventing a player from taking a full part in all training and match play activities typically planned for that day, where the injury has been there for a period $>24$ hours from midnight at the end of the day that the injury was sustained. ${ }^{11}$

An observation period of 12 weeks from the day of testing as team personnel could not guarantee access for repeat testing. Additionally, significant changes in eccentric knee flexor strength have been reported within 16 weeks. ${ }^{5}$ Thus, we could not account for changes in strength at or beyond this time point as no follow-up testing could be completed.

\section{3 | Data analysis}

All data were analyzed using SPSS (version 21.0; IBM, Inc). Figures were generated using previously published code. ${ }^{12}$ Descriptive statistics were used to report performance markers. Data are presented as mean values with standard deviations and $95 \%$ confidence intervals $(95 \% \mathrm{CI})$. Confidence intervals are reported to understand the range surrounding the mean values for each investigated metrics. Strength metrics are presented as interquartile ranges (IQR) and mean between left and right limbs. The maximum and average forces between limbs across all three repetitions were compared to report percentage imbalances. Between-limb imbalances were calculated using the following formula: (maximum value - minimum value)/ maximum value. 
Players with a previous hamstring injury within 12 months prior to testing were compared to their uninjured peers using the mean values for maximum and average force of both limbs. Return to sport was confirmed once medical clearance was obtained for full, unrestricted participation in all team training and matches.

An independent-samples $t$ test was used to compare mean values between the following data: players with and without a substantial problem at testing, players with and without a previous hamstring injury, players that did and did not sustain a hamstring injury during the study period, and limbs that did and did not sustain a hamstring injury during the study period. Players were allocated to specific sub-groups based on demographic information (ie, age, playing position) and eccentric knee flexor strength quartile ranges. A linear regression was used to evaluate the likelihood of sustaining a hamstring injury relative to all other sub-groups based on quartiles. Significance was set at a $P<.05$.

In total, three outcomes metrics were used to investigate the risk within and between sub-groups: risk (ie, likelihood of sustaining a time-loss hamstring injury occurring within 12 weeks from testing), odds ratio (ie, odds of sustaining an injury in a specific sub-group relative to all others), and posttest probability (ie, likelihood of sustaining injury given the known population prevalence and individual test result).

\subsection{Ethical approval}

Player anonymity was maintained and data protection assured in accordance with ethical approval received from the University Research Ethics Committee.

\section{3 | RESULTS}

\section{1 | Injury history in the $\mathbf{1 2}$ months prior to testing}

In total, 185 elite male Gaelic football players participated in the study. Sixty percent of players $(n=111)$ sustained a previous time-loss injury in the 12 months prior to testing. One-in-four players $(25.4 \% ; n=47)$ sustained a previous hamstring time-loss injury within 12 months prior to testing. The proportion of previous hamstring time-loss injuries classified as mild (1-7 days), moderate (7-28 days), or severe (>28 days) was $15.5 \%, 38.2 \%$, and $46.4 \%$, respectively.

The mean period between return to sport following a prior hamstring injury and testing was 23 weeks (95\% CI 18-28). The proportion of players that returned to sport following hamstring time-loss injury within 4 weeks, 5-16 weeks, or 17-52 weeks prior to testing was $20.5 \%, 28.2 \%$, and $51.3 \%$, respectively.

\section{2 | Musculo-skeletal complaints in the 7 days prior to testing}

Symptoms and health complaints during the 7 days prior to testing were reported by $35.7 \%$ (95\% CI 30.1-41.3) of players. The prevalence of difficulties in normal training and competition due to injury, illness, or health problems in the 7 days prior to testing was $35.7 \%$ (95\% CI 30.1-41.3). However, $40.8 \%$ (95\% CI 35.1-46.5) reported training volume reductions and $31.6 \%$ (26.2-37.1) reported performance reductions due to health problems during the same period. Substantial problems were reported in $15.1 \%$ (95\% CI 10.0-20.3) of players $(\mathrm{n}=28)$. None of these health problems required more than 24-hours time-loss from sport. Thus, no participant was excluded on the basis of this questionnaire as all had medical clearance to participate in unrestricted training and competition.

\section{3 | Eccentric knee flexor strength during testing}

The mean between-limb maximum force was $363 \pm 86 \mathrm{~N}$ (95\% CI 349-375), while average force was $336 \pm 86 \mathrm{~N}$ (95\% CI 323-348). The between-limb imbalances associated with maximum and average forces were $9.2 \% \pm 7.2$ (95\% CI 8.2-10.3) and $8.9 \% \pm 6.9$ (95\% CI 7.9-10.0), respectively.

No differences in between-limb maximum force $(P=.430)$, average force $(P=.693)$, maximum force imbalances $(P=.064)$, or average force imbalances $(P=.401)$ were found between players tested at preseason or early National League cycle (Table 1).

\subsection{Injury history and eccentric knee flexor strength during testing}

No differences in between-limb maximum force $(P=.461)$, average force $(P=.761)$, maximum force imbalances $(P=.662)$, or average force imbalances $(P=.367)$ were found between players with or without substantial problems in the week prior to testing. Confidence intervals in Table 1 also indicate that a previous time-loss injury in the 12 months prior to testing had no difference on eccentric knee flexor strength.

\section{5 | Injury outcomes following testing}

Twenty-eight players (15.7\%; 95\% CI 12.0-19.4) sustained a time-loss hamstring injury following testing. Hamstring injury risk was $16.4 \%$ (95\% CI 11.1-21.7) among senior players and $14.5 \%$ (95\% CI 9.4-19.6) among under-20 
TA B L E 1 Eccentric knee flexor strength between groups based on testing time and injury history

\begin{tabular}{|c|c|c|c|c|c|}
\hline & $\begin{array}{l}\text { Sample } \\
\text { size }\end{array}$ & Max force (n) & $\begin{array}{l}\text { Max force } \\
\text { imbalance }\end{array}$ & Average force (n) & $\begin{array}{l}\text { Average force } \\
\text { imbalance }\end{array}$ \\
\hline \multicolumn{6}{|l|}{ Player testing cycle } \\
\hline National league & 24 & $350(315-385)$ & $6.7 \%(4.7-8.7)$ & $329(295-364)$ & $7.8 \%(5.2-10.4)$ \\
\hline \multicolumn{6}{|l|}{ OSTRQ responses } \\
\hline Substantial problem & 28 & $354(332-377)$ & $9.8 \%(7.5-12.4)$ & $331(306-356)$ & $10.0 \%(7.3-13.1)$ \\
\hline \multicolumn{6}{|l|}{ Hamstring injury history } \\
\hline Uninjured players & 270 & $357(347-367)$ & $8.6 \%(7.8-9.4)$ & $328(319-339)$ & $8.3 \%(7.6-9.1)$ \\
\hline Injured limb of injured players & 44 & $388(359-417)$ & $10.6 \%(8.6-12.6)$ & $365(336-395)$ & $9.9 \%(8.0-11.8)$ \\
\hline
\end{tabular}

Note: Data are mean values with 95\% confidence intervals (95\% CI). OSTRQ = Oslo Sports Trauma Research Center Questionnaire on Health Problems; OSTRQ responses refers to report of health problems within $7 \mathrm{~d}$ prior to testing. Substantial health problems were classified as any injury or illness "leading to moderate or severe reductions in training volume, or moderate or severe reductions in sports performance, or complete inability to participate in sport." Hamstring injury history refers to time-loss hamstring injuries sustained within 12 mo prior to testing.

players. Hamstring injury risk was $15.5 \%$ (95\% CI 10.3 20.7 ) and $16.7 \%$ (95\% CI 11.3-20.3) among players tested at preseason and National League cycles, respectively. The proportion of hamstring time-loss injuries classified as mild (1-7 days), moderate (7-28 days), or severe (>28 days) was $21.4 \%(n=6), 60.7 \%(n=17)$, and $17.9 \%$ $(\mathrm{n}=5)$, respectively.

\subsection{Associations with hamstring injury}

Players that did not sustain a hamstring injury had greater average between-limb asymmetries (uninjured group $=9.1 \%$,
95\% CI 7.8-10.1; injured group $=5.1 \%, 95 \%$ CI 3.7-6.7; $P=.001)$. No other differences were found between groups.

No statistically significant $(P=.585)$ max force differences were found between injured (354 N, 95\% CI 326-382) and uninjured limbs (364 N, 95\% CI 355-374) (Figure 1). Likewise, no statistically significant $(P=.704)$ average force differences were found between injured (330 N, 95\% CI 300357 ) and uninjured limbs (336 N, 95\% CI 327-347). A hamstring injury occurred in $7.0 \%(95 \%$ CI $2.9-11.0 ; n=12)$ of limbs that generated greater max force than the contralateral side. On average, these stronger limbs that sustained a hamstring injury produced $6.0 \%$ (95\% CI 4.3-7.5) more force during testing in comparison with the contralateral side.
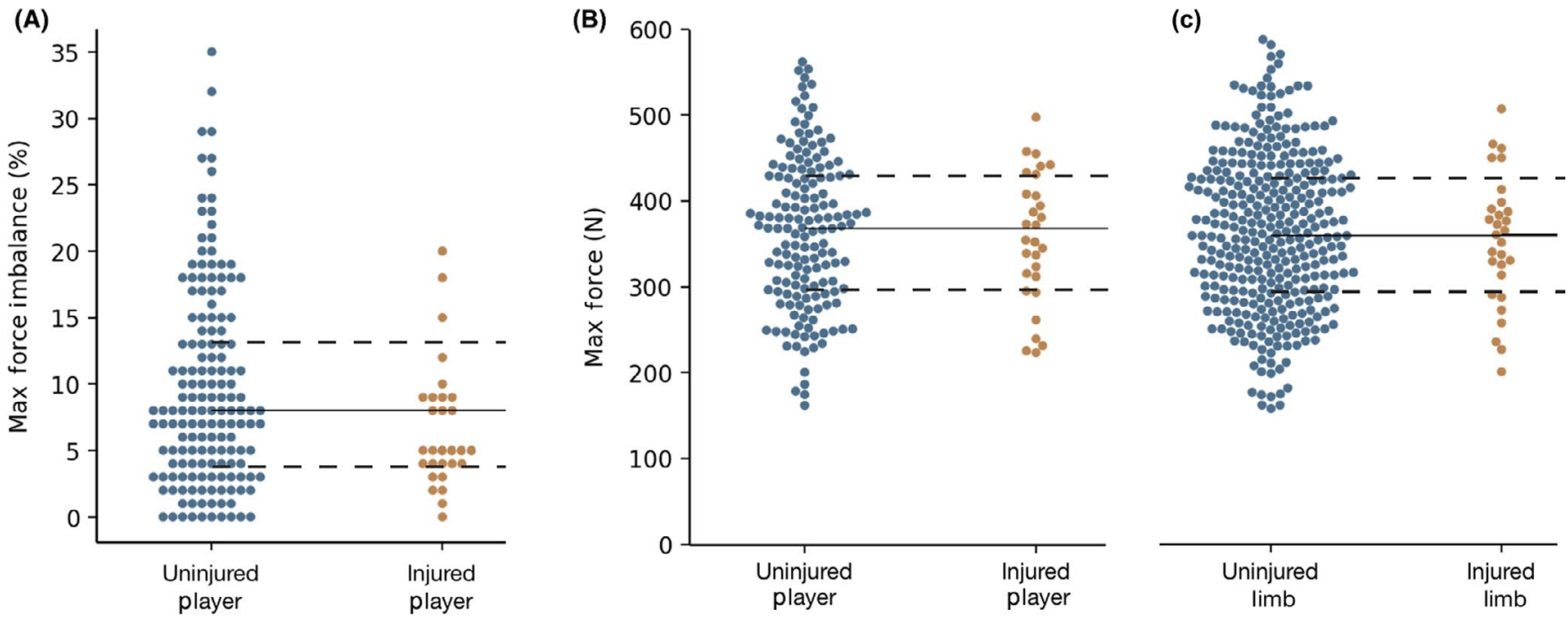

F I G U RE 1 Eccentric knee flexor strength in injured and uninjured sub-groups. Data points represent test results for individual participants ( $n=185$ ) according to (A) maximum force imbalance (\%) between limbs per player, (B) maximum force averaged between two limbs per player, and (C) maximum force per limb. Straight lines represent median values. Dashed lines represent interquartile ranges 
T A B L E 2 Relationship between player demographics and hamstring injury risk in elite Gaelic football

\begin{tabular}{|c|c|c|c|c|c|c|c|}
\hline & $\begin{array}{l}\text { Number of } \\
\text { players }\end{array}$ & $\begin{array}{l}\text { Number of } \\
\text { uninjured } \\
\text { players }\end{array}$ & $\begin{array}{l}\text { Number of } \\
\text { players with } \\
1+\text { hamstring } \\
\text { injury }\end{array}$ & Sub-group risk & $\begin{array}{l}\text { Risk to other } \\
\text { players }\end{array}$ & Odds ratio & Post-test probability \\
\hline \multicolumn{8}{|l|}{ Time-loss injury history } \\
\hline $\begin{array}{l}\text { Any Injury < } 12 \text { mo } \\
\text { RTS }\end{array}$ & 111 & 92 & 19 & $17.1 \%(11.7-22.5)$ & $16.2 \%(10.9-21.5)$ & $1.07(0.48-2.35)$ & $20.7 \%(14.8-26.5)$ \\
\hline $\begin{array}{l}\text { Hamstring } \\
\text { Injury < } 12 \text { mo } \\
\text { RTS }\end{array}$ & 47 & 38 & 9 & $19.2 \%(13.5-24.8)$ & $14.5(9.4-19.6)$ & $1.40(0.59-3.33)$ & $23.7 \%(17.6-29.8)$ \\
\hline \multicolumn{8}{|l|}{ Age group } \\
\hline $18-20$ & 78 & 67 & 11 & $14.1 \%(8.9-19.4)$ & $19.8 \%(13.8-25.8)$ & $0.67(0.29-1.51)$ & $16.4 \%(10.8-22.0)$ \\
\hline $21-24$ & 36 & 28 & 8 & $22.2 \%(16.0-28.5)$ & $15.8 \%(10.3-21.3)$ & $1.52(0.61-3.80)$ & $28.6 \%(21.8-35.4)$ \\
\hline $25-29$ & 45 & 36 & 9 & $20.0 \%(14.0-26.0)$ & $16.1 \%(10.6-21.7)$ & $1.30(0.54-3.11)$ & $25.0 \%(18.5-31.5)$ \\
\hline $30+$ & 10 & 9 & 1 & $10.0 \%(5.5-14.5)$ & $17.6 \%(11.9-23.4)$ & $0.52(0.06-4.27)$ & $11.1 \%(6.4-15.9)$ \\
\hline \multicolumn{8}{|l|}{ Main playing position } \\
\hline Goalkeeper & 4 & 4 & 0 & - & $18.5 \%(13.2-23.8)$ & - & - \\
\hline Full back line & 22 & 20 & 2 & $9.1 \%(4.0-14.2)$ & $19.8 \%(12.8-26.8)$ & $0.41(0.09-1.88)$ & $10.0 \%(4.7-15.3)$ \\
\hline Half back line & 33 & 27 & 6 & $18.2 \%(11.4-25.0)$ & $17.8 \%(11.0-24.5)$ & $1.03(0.36-2.90)$ & $22.2 \%(14.9-29.6)$ \\
\hline Midfield & 16 & 12 & 4 & $25.0 \%(17.4-32.7)$ & $16.8 \%(10.2-23.4)$ & $1.65(0.48-5.69)$ & $33.3 \%(25.0-41.7)$ \\
\hline Half forward line & 24 & 17 & 7 & $29.2 \%(21.1-37.2)$ & $15.2 \%(8.8-21.5)$ & $2.31(0.82-6.51)$ & $41.2 \%(32.5-49.9)$ \\
\hline Full forward line & 24 & 21 & 3 & $12.5 \%(6.7-18.3)$ & $19.2 \%(12.2-26.2)$ & $0.60(0.16-2.23)$ & $14.3 \%(8.1-20.5)$ \\
\hline
\end{tabular}

Note: Data are mean values with $95 \%$ confidence intervals $(95 \% \mathrm{CI})$. Risk refers to probability of sustaining a time-loss hamstring injury within 12 wk from testing.

Similarly, a hamstring injury occurred in 8.8\% (95\% CI 4.7$13.5 ; \mathrm{n}=15$ ) of limbs that generated less max force than the contralateral side. On average, weaker limbs that sustained a hamstring injury produced $7.9 \%$ (95\% CI 5.3-11.2) less force during testing in comparison with the contralateral side.

Player demographics (Table 2), strength metrics (Table 3), and expressing an individual's strength profile relative to all other players (Table S1) or their teammates (Table S2) did not assist in identifying those at increased risk.

\section{4 | DISCUSSION}

The aim of the current study was to evaluate whether knee flexor strength altered susceptibility to hamstring injury in elite Gaelic football. No investigated demographic or eccentric knee flexor strength metric was associated with hamstring injury risk. Thus, the current study does not support the use of eccentric knee flexor strength monitoring to determine the injury risk among elite Gaelic football players.

\section{1 | Base rate}

Overall, $16 \%$ of elite Gaelic football players sustained a hamstring injury during a 12 -week period. This level of risk is similar to previous reports in elite Gaelic football $(21 \%, 95 \%$
CI 19-23). ${ }^{1}$ Thus, it appears that $80 \%-84 \%$ of players will not sustain a hamstring injury each season.

Practitioners should be aware that a previous epidemiological investigation established that in elite Gaelic football, the median number of time-loss hamstring injuries per team is 9 each season. ${ }^{1}$ Considering a team of 38 players may complete 100 sessions per season with $80 \%$ player availability (3800 player sessions $\times 80 \%=3040$ player sessions), the estimated risk of hamstring injury in any given player session is $0.3 \%$. Framing the risk of hamstring injury in this manner may assist in developing realistic expectations when investigating risk factors for exceptionally rare events.

\subsection{Comparing findings to previous investigations}

The findings of the current study do not support the modification of hamstring injury risk management strategies based on eccentric knee flexor strength metrics. No association with eccentric knee flexor strength and hamstring injury risk was also observed in elite Qatari soccer players $(n=544$ player seasons; $12 \%$ risk). ${ }^{7}$ However, among elite rugby union players ( $\mathrm{n}=178 ; 11 \%$ risk), in a sub-group with between-limb imbalances $>20 \%$ ( $28 \%$ of the sample), hamstring injury risk was 3.4 times (95\% CI 1.5-7.6) greater relative to other players. ${ }^{4}$ Similarly, in elite Australian soccer $(\mathrm{n}=152 ; 18 \%$ risk), players with maximum eccentric knee flexor strength 
T A B L E 3 Relationship between eccentric knee flexor strength and hamstring injury risk in elite Gaelic football

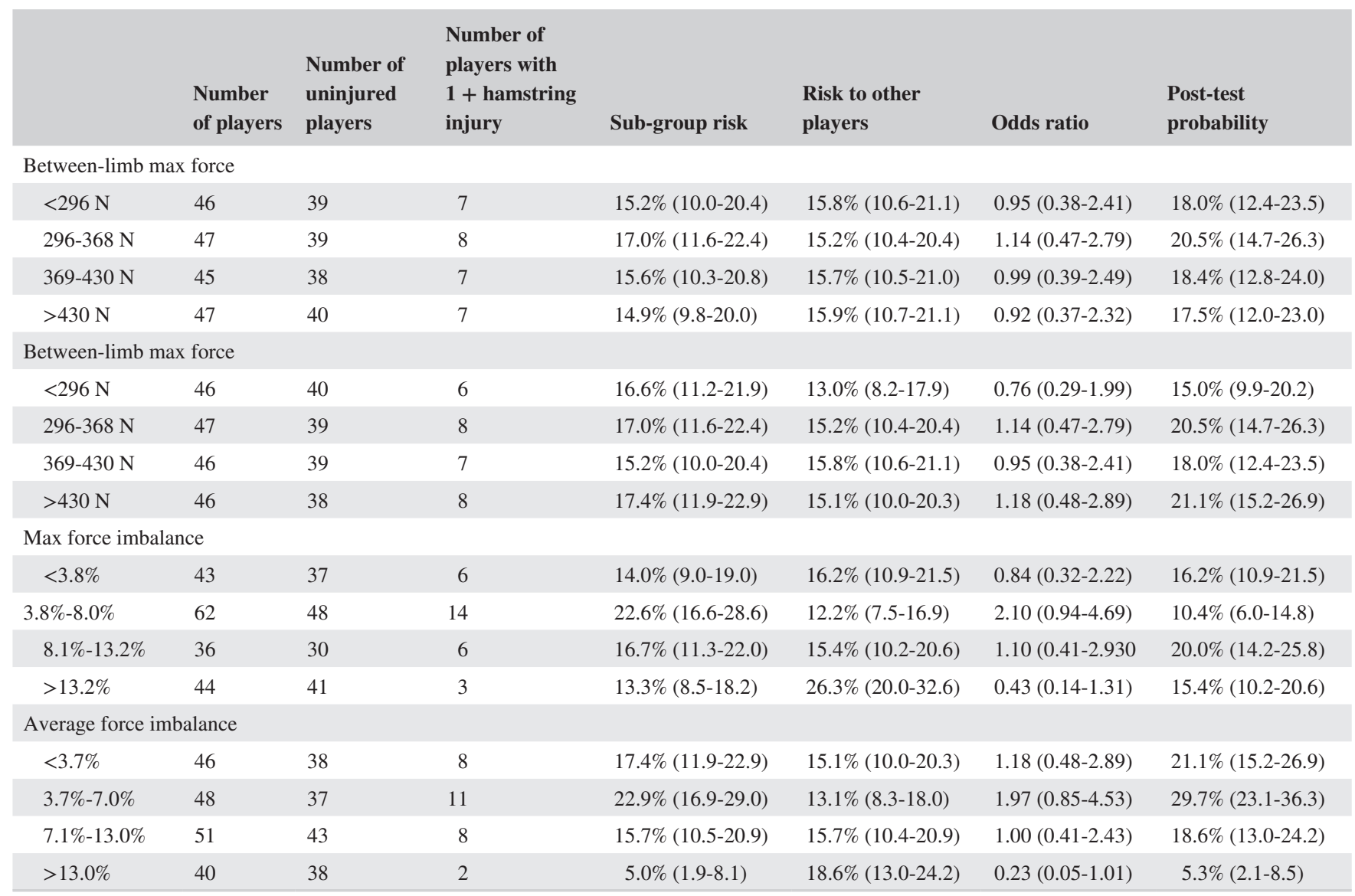

Note: Data are mean values with $95 \%$ confidence intervals $(95 \% \mathrm{CI})$. Risk refers to probability of sustaining a time-loss hamstring injury within 12 wk from testing.

$<337 \mathrm{~N}$ ( $63 \%$ of sample) had a RR of 4.4 (95\% CI 1.7-17.5) compared to other players. ${ }^{6}$ Likewise, in a study on elite AFL players ( $\mathrm{n}=21 ; 13 \%$ risk), a threshold of $<256 \mathrm{~N}$ (39\% of sample) was associated with a RR of 2.7 (95\% CI 1.3-5.5). ${ }^{5}$

As injuries happen to individual athletes, and not to organizations or teams, the ranges of screening test scores associated with injury need to be considered if these data are to inform athlete management strategies. Despite statistically significant differences between mean eccentric knee flexor strength of injured and uninjured limbs being previously reported in elite rugby union, wide ranges are observed when the standard deviation is considered for injured limbs (274-436 N), uninjured limbs of injured players (278-542 N), and limbs of uninjured players (283-453 N). ${ }^{4}$ Similar ranges were reported in elite Australian soccer players for injured limbs (178-344 N), uninjured limbs of injured players (200-326 N), and limbs of uninjured players (237-383 N). ${ }^{6}$ Likewise, profiles in elite soccer players from Qatar also overlapped for injured limbs (245-379 N), uninjured limbs of injured players (241-363 N), and limbs of uninjured players $(228-370 \mathrm{~N}) .^{7}$ These wide ranges question the practical utility in correctly identifying athletes at increased risk of hamstring injury by using an eccentric knee flexor strength test.
Between-limb imbalances indicate the magnitude of difference in strength between limb; however, the arbitrariness of strength cut-off values remains a contentious issue. ${ }^{13} \mathrm{~A}$ threshold of $20 \%$ has been previously used to indicate significant clinical weakness between limbs. ${ }^{14}$ Figure 1 indicates that no player with an imbalance $>20 \%$ sustained a hamstring injury. Similarly, Table 2 indicates that 90\% (26/29) of hamstring injuries were sustained by players with a between-limb imbalance $<13.2 \%$. Thus, unilateral hamstring weakness, as measured during the current bilateral eccentric knee flexor test, appears not to increase the risk of sustaining a subsequent hamstring injury.

\section{3 | Health problems and injury prior to testing}

In the current study, $41 \%$ of players reported reduced training volumes due to physical complaints experienced within the 7 days prior to testing. However, eccentric knee flexor strength metrics did not differ between groups that did or did not report substantial health problems in the 7 days prior to testing.

One-in-four players had sustained a hamstring within the 12 months prior to testing; however, the average time 
since return to sport was 23 weeks. We previously reported no statistically significant difference in maximum eccentric knee flexor strength between elite Gaelic football players with a previous hamstring injury $(367 \mathrm{~N} ; 95 \% \mathrm{CI}$ $347-387)$ compared to their uninjured peers $(350 \mathrm{~N} ; 95 \%$ CI 338-362). ${ }^{8}$

The current study also found that injury history did not alter the risk of sustaining a hamstring injury. The lack of effect of previous injury on subsequent risk may be attributable to findings in previous epidemiological investigations in elite Gaelic football that found most players will have sustained an injury in the 12 months prior to testing. ${ }^{15}$ Thus, among populations with a high risk of injury, classifying risk profiles on the basis of prior injury may be of limited value, as most of the population will have already been affected in the past.

\subsection{Follow-up time to achieve meaningful differences}

The current study followed elite Gaelic football players for 12 weeks following testing. This is shorter than observational periods used in elite Australian football (1628 weeks), elite Australian soccer (8-32 weeks), and elite Qatari soccer (44 weeks). ${ }^{5-7}$ However, among elite AFL players, eccentric knee flexor strength can increase by $10 \%$ within 16 weeks from $301 \pm 84 \mathrm{~N}$ to $330 \pm 73 \mathrm{~N}$ following preseason training. ${ }^{7}$ Similarly, in recreationally active males, exposure to low- or high-volume eccentric strength training can increase in eccentric knee flexor strength by $142 \mathrm{~N}(95 \%$ CI 49-235) and $112 \mathrm{~N}$ (95\% CI 19-204) within 6 weeks, respectively. ${ }^{16}$ Thus, future studies should consider establishing the minimum time to observe a change in performance beyond the typical error of measurement and deploy these findings in risk factor identification studies using ongoing athlete screening.

\subsection{Remembering the mechanism of injury}

Three-in-four hamstring injuries in elite Gaelic football occur during running-related tasks. ${ }^{1}$ Despite positive associations reported between rate of force development during a prone isometric hamstring strength test and sprint performance, $78 \%-83 \%$ of the variance in sprint performance is explained by factors other than isometric strength. ${ }^{17}$ Thus, understanding the factors causing sprinting performance, a task completed thousands of times without the onset of injury or related symptoms, to lead to injury may be a more insightful approach to monitoring hamstring injury risk than strength testing.

\section{5 | PERSPECTIVE}

The current study investigated whether knee flexor strength and between-limb imbalances impact susceptibility to hamstring injury in elite Gaelic football. No relationship was found in a sample of 185 players followed for 12 weeks following testing. Practitioners should avoid anchoring their perceptions of an athlete's risk of sustaining a hamstring injury using eccentric knee flexor strength data.

\section{ACKNOWLEDGEMENTS}

MR received an unrestricted educational grant from the Gaelic Athletic Association. The authors wish to thank the participating team staff and players for their contribution to the current research project.

\section{ORCID}

Mark Roe (D) https://orcid.org/0000-0001-6615-2283

Shane Malone (iD https://orcid.org/0000-0002-0177-9365

\section{REFERENCES}

1. Roe M, Murphy JC, Gissane C, Blake C. Hamstring injuries in elite Gaelic football: an 8-year investigation to identify injury rates, time-loss patterns and players at increased risk. $\mathrm{Br}$ J Sports Med. 2018;52:982-988. https://doi.org/10.1136/bjspo rts-2016-096401

2. Al Attar W, Soomro N, Sinclair P, et al. Effect of injury prevention programs that include the nordic hamstring exercise on hamstring injury rates in soccer players: a systematic review and meta-analysis. Sports Med. 2017;47(5):907-916. https://doi.org/10.1007/ s40279-016-0638-2

3. Ekstrand J, Waldén M, Hägglund M. Hamstring injuries have increased by $4 \%$ annually in men's professional football, since 2001: a 13-year longitudinal analysis of the UEFA Elite Club injury study. Br J Sports Med. 2016;50(12):731-737.

4. Bourne MN, Opar DA, Williams MD, Shield AJ. Eccentric knee flexor strength and risk of hamstring injuries in rugby union: a prospective study. Am J Sports Med. 2015;43(11):2663-2670.

5. Opar DA, Williams MD, Timmins RG, Hickey J, Duhig SJ, Shield AJ. Eccentric hamstring strength and hamstring injury risk in Australian footballers. Med Sci Sports Exerc. 2015;47:857-865.

6. Timmins R, Bourne M, Shield AJ, et al. biceps femoris fascicles and eccentric knee flexor weakness increase the risk of hamstring injury in elite football (soccer): a prospective cohort study. $\mathrm{Br} \mathrm{J}$ Sports Med. 2016;50:1524-1535.

7. van Dyk N, Bahr R, Burnett AF, et al. A comprehensive strength testing protocol offers no clinical value in predicting risk of hamstring injury: a prospective cohort study of 413 professional football players. Br J Sports Med. 2017;51(23):1695-1702. https://doi. org/10.1136/bjsports-2017-097754

8. Roe M, Malone S, Delahunt E, et al. Eccentric knee flexor strength profiles of 341 elite male academy and senior Gaelic football players: Do body mass and previous hamstring injury impact performance? Phys Ther Sport. 2018;31:68-74. 
9. Clarsen B, Rønsen O, Myklebust G, Flørenes TW, Bahr R. The Oslo Sports Trauma Research Center questionnaire on health problems: a new approach to prospective monitoring of illness and injury in elite athletes. Br J Sports Med. 2014;48(9):754-760.

10. Opar DA, Piatkowski T, Williams MD, Shield AJ. A novel device using the Nordic hamstring exercise to assess eccentric knee flexor strength: a reliability and retrospective injury study. J Orthop Sports Phys Ther. 2013;43:636-640.

11. Brooks J, Fuller CW, Kemp SP, Reddin D. Epidemiology of injuries in English professional rugby union: part 1 match injuries. $\mathrm{Br}$ J Sports Med. 2005;39:757-766.

12. Ho J, Tumkaya T, Aryal S, Choi H, Claridge-Chang A.Moving beyond $\mathrm{P}$ values: Everyday data analysis with estimation plots. https://doi.org/10.1101/377978

13. Bahr R. Why screening tests to predict injury do not workand probably never will...: a critical review. Br J Sports Med. 2016;50:776-780.

14. Sapega AA. Muscle performance evaluation in orthopaedic practice. J Bone Joint Surg Am. 1990;72(10):1562-1574.

15. Roe M, Murphy JC, Gissane C, Blake C. Time to get our four priorities right: an 8-year prospective investigation of 1326 playerseasons to identify the frequency, nature, and burden of time-loss injuries in elite Gaelic football. PeerJ. 2018;6:e4895.
16. Presland JD, Timmins RG, Bourne MN, Williams MD, Opar DA. The effect of Nordic hamstring exercise training volume on biceps femoris long head architectural adaptation. Scand J Med Sci Sports. 2018;28(7):1775-1783.

17. Ishøi L, Aagaard P, Nielsen MF, et al. The Influence of Hamstring Muscle Peak Torque and Rate Of Torque Development for Sprinting Performance in Football Players: A Cross-Sectional Study. Int J Sports Physiol Perform. 2018;14:1-27.

\section{SUPPORTING INFORMATION}

Additional supporting information may be found online in the Supporting Information section.

How to cite this article: Roe M, Delahunt E, McHugh M, et al. Association between eccentric knee flexor strength and hamstring injury risk in 185 elite Gaelic football players. Scand J Med Sci Sports. 2020;00:1-8. https://doi.org/10.1111/sms.13588 